\title{
Changes in health-related quality of life after orthognathic surgery: a multicenter study
}

\author{
Valentina Duarte ${ }^{1,2,3}$ (1) Carlos Zaror ${ }^{4,5} \cdot$ Julio Villanueva $^{6,7} \cdot$ Fabiola Werlinger $^{8} \cdot$ Constanza Vidal $^{2} \cdot$ Pedro Solé $^{9,10}$. \\ Juan Alberto O Ryan $^{9} \cdot$ Roberto Requena $^{9,10}$ - Matías Dallaserra ${ }^{6} \cdot$ René Rojas $^{11}$ - Marcela Burgos ${ }^{12}$. \\ Montse Ferrer ${ }^{13,14,15}$
}

Received: 5 August 2021 / Accepted: 22 November 2021 / Published online: 2 December 2021

(c) The Author(s), under exclusive licence to Springer-Verlag GmbH Germany, part of Springer Nature 2021

\begin{abstract}
Objective To evaluate changes in general and oral health-related quality of life (HRQoL) in patients with dentofacial deformity undergoing orthognathic surgery, and whether these changes vary according to type of deformity.

Material and methods This is a prospective longitudinal multicenter study of patients with dentofacial deformities $(n=90)$. The Orthognathic Quality of Life Questionnaire (OQLQ), Oral Health Impact Profile (OHIP-14), and Short-Form Health Survey version2 (SF-36v2) were self-completed by patients before surgery, 3 and 6 months after orthognathic surgery. Change was tested using paired $t$-test, and compared between Class II and Class III of dentofacial deformity by unpaired $t$-test. The magnitude of change was examined estimating the standardized response mean (SRM).

Results The OQLQ and OHIP-14 showed statistically significant improvements 6 months after surgery, compared with the pre-surgical evaluation, but the SF-36v2 only in the physical component summary. The SRM was large in OQLQ oral function $(-1.11)$ and dentofacial facial aesthetics (-0.76) dimensions, and moderate in most of OHIP-14 dimensions. Differences in mean change between Class II and III were statistically significant for global scores of OQLQ $(-10.08$ vs $-20.30, p=0.0271)$ and OHIP-14 (-3.79 vs $-10.56, p=0.0144)$.

Conclusions A significant improvement was observed in oral HRQoL and in the physical component of general health in patients with dentofacial deformities Class II and III after orthognathic surgery. Improvement was greater among Class III than in Class II patients.

Clinical relevance These results provide patients, oral health care professionals, and planners with valuable information to make evidence-based decisions and facilitate shared clinical decision-making, taking into account the patients' perspective.
\end{abstract}

Keywords Oral health-related quality of life $\cdot$ Orthognathic surgery $\cdot$ Patient-reported outcome measures $\cdot$ Dentofacial deformity $\cdot$ Health-related quality of life

\section{Introduction}

Patients with dentofacial deformities may require a comprehensive orthodontic and surgical approach to correct moderate and serious dentofacial deformities $[1,2]$. The conventional 3-phase technique includes orthodontic treatment prior to and after orthognathic surgery [3]. Pre-surgical orthodontics aims to achieve correct occlusion through cephalometric prediction, while the post-surgical treatment allows maintaining the final occlusion achieved and

Valentina Duarte

valitaduarte@gmail.com

Extended author information available on the last page of the article its long-term stability by settling and levelling the arches, ensuring good root parallelism, and performing detailed tooth positioning [4]. The duration of orthodontic treatment varies from 27.9 [5] to 21.9 months, with a median presurgical duration of 15.4 months, and of 5.9 months post-surgery [6]. Each patient requires a variable length of preoperative orthodontics, followed by a relatively constant period of post-surgical orthodontic treatment to obtain the final occlusion [4].

Health-Related Quality of Life (HRQoL) is an important patient-reported outcome to evaluate the impact of therapeutic interventions on health [7]. Patient-reported outcomes are increasingly being used to provide complementary and additional insight into the health status of patients 
[8]. Disease-specific patient-reported outcomes may show intervention-related changes more precisely than the generic ones, applicable to all populations [9]. The Orthognathic Quality of Life Questionnaire (OQLQ) is the only instrument specifically designed to measure Oral Health-Related Quality of Life (OHRQoL) in patients with dentofacial deformities $[10,11]$, to evaluate the benefit of orthognathic surgery from the patients' point of view. The Spanish version of the OQLQ was validated in Chile demonstrating good validity, reliability, and responsiveness [12].

The comprehensive orthodontic and surgical approach to correct dentofacial deformities has shown important benefits measured with patient-reported outcomes [11, 13-17], and the efficacy of orthognathic surgery has been also demonstrated by cost-utility analysis [18]. However, studies measuring both general and oral HRQoL [11, 15-17] included small sample sizes (from 14 to 60 patients) [11, 16, 17], except for Khadka et al. $(n=110)$ [15]. Moreover, there are few studies analyzing Class II and Class III dentofacial deformities separately [13, 19-21], although significant differences have been reported between both classes in preoperative psychologic profiles and postoperative dynamics of patients [22]. The presurgical orthodontic treatment can further affect OHRQoL in patients with Class III malocclusion, as the necessary decompensation strongly emphasizes skeletal disharmony in these patients [23].

The aim of the study was to evaluate changes in general and oral HRQoL in patients with dentofacial deformity treated by orthognathic surgery, and to examine whether these changes vary according to type of deformity.

\section{Methods}

\section{Study design}

This is a prospective longitudinal multicenter study of patients with dentofacial deformities recruited from three public hospitals and two private clinics, registered in ClinicalTrials.gov (register ID: NCT04863170). The inclusion criteria were adult patients over 18 years old with dentofacial deformity Class II or III selected for orthodontic treatment and orthognathic surgery, regardless the extent of their dysgnathia. Patients with congenital abnormalities such as craniofacial syndrome or cleft lip/palate and sequels due to maxillofacial trauma were excluded.

Patients were examined by clinical and cephalometric analysis to be classified into Class II or Class III by dentofacial deformity. Edward Angle (1899) classified Orthodontic malocclusion into Class I, II and III based on the mesiodistal relationship of the 1st permanent molars, considered as the key ridge teeth [24]. Depending on the relationship between the upper first molar and the lower first molar: Class
I presents normal molar relationship, but there is crowding or misalignment of the teeth, cross bites, among other irregularities; Class II malocclusion is defined as the mesiobuccal cusp of the upper first molar being mesially (anteriorly) positioned relative to the buccal groove of the lower first molar; while in Class III, the mesiobuccal cusp of the upper first molar is distally (posteriorly) positioned relative to the buccal groove of the lower first molar [25]. Malocclusion may be associated with skeletal abnormalities [26] and reflect maxillo-mandibular disharmony defined for skeletal Class II as underdevelopment of mandibular growth and/or maxillary excess, leading to a facial convex profile and for skeletal Class III when discrepancies are caused by maxillary retrognathia and/or mandibular protrusion (concave profile) [27].

Orthognathic treatment was conducted in a conventional three-stage approach, including pre-surgical orthodontics, surgery, and post-surgical orthodontics. Written consent was obtained from the patients during the first evaluation visit in the presurgical stage. The study was approved by the ethics committee of Valparaíso-San Antonio Health Service.

\section{Data collection and instruments}

Patient-reported outcomes were collected at three time points: during the orthodontic treatment 1 to 2 weeks before surgery (T1), 3 months (T2), and 6 months after orthognathic surgery (T3). All patients at T2 and T3 were under post-surgical orthodontic treatment with a fixed appliance. Patients were asked to self-complete the socio-demographic data, the motivation for treatment, and the following three questionnaires: the Orthognathic Quality of Life Questionnaire (OQLQ) [10, 11], the Short-Form Oral Health Impact Profile (OHIP-14) [28], and the Short-Form Health Survey version 2 (SF-36v2) [29].

The OQLQ consists of 22 questions which are answered on a 5-point Likert scale $[10,11]$ ranging from "does not bother me at all" (0) to "bothers me a lot" (4). This questionnaire covers 4 domains of oral HRQoL: dentofacial aesthetics impact (items $1,7,10,11$, and 14; score range 0 to 20), oral function (items 2 to 6 ; score range 0 to 20), awareness impact (items $8,9,12$, and 13; score range 0 to 16), and social impact (items 15 to 22 ; score range 0 to 32 ) $[7,8,30,31]$. The scores of the questionnaire are obtained by the arithmetic sum of the points in each item or question as reported by Cunningham et al.[10] A total score is also calculated with a theoretical minimum of 0 points $(22$ $* 0$ ), and a theoretical maximum of 88 points $(22 * 4)$. A lower score reflects a better oral HRQoL. Missing data were estimated by a simple allocation method from the mean of those items that were available in each dimension of the questionnaire [32].

The OHIP-14 consists of 14 items covering 7 domains of oral HRQoL: Functional limitation, Physical pain, 
Psychological discomfort, Physical disability, Psychological disability, Social disability, and Handicap [28]. Items are answered through a Likert scale with values ranging from 0 to 4: never, almost never, occasionally, frequently and very frequently. Summary OHIP-14 scores can range from 0 to 56, higher scores indicating worse HRQoL [33].

The SF-36v2 questionnaire consists of 36 items covering 8 domains of general HRQoL: Physical functioning, Role-physical, Bodily pain, General health, Vitality, Social functioning, Role-emotional, and Mental health [34, 35]. Scores for dimensions and for physical and mental component summaries (PCS and MCS) were constructed using the recommended scoring algorithms [35]. SF-36v2 scores were standardized to have a mean of 50 and standard deviation of 10 in the US general population. Higher scores indicate better HRQoL [29].

A Global Transition Scale was administered to patients at each post-surgical follow-up time (T2 and T3), asking to compare their current oral health with before surgery, with three response options: better, about the same, or worse. If patients stated that they had improved, they were asked how much, responding on a six-point scale [36]. Patients stating that they had worsened also specified how much on a scale of six response options. Patients who said they were about the same had three response options to specify if there was any slight modification. Thus, we had a 15-point global rating scale for changes from -7 (a very great deal worse), through 0 (no change) to +7 (a very great deal better).

\section{Sample size}

Accepting an alpha risk of 0.05 and a beta risk of 0.2 in a two-sided test, 33 subjects are necessary to recognize as statistically significant a paired difference of 0.5 SRM or greater. To allow stratified analysis by class, a total of 80 participants are needed assuming a drop-out rate of $20 \%$ and a balanced distribution between Class II and Class III.

\section{Data analysis}

Descriptive statistics were used to examine frequency and distribution of the sample's sociodemographic data. Characteristics of patients by type of dentofacial deformity were compared using Chi-squared or Fisher's Exact tests.

The mean (SD) of general and oral health-related quality of life (HRQoL) scores was calculated at baseline and at each follow-up time (T1, T2, and T3). Changes were tested using parametric test (paired $t$-test). The magnitude of the change was examined using the Standardized Response Mean (SRM), an indicator based on the distribution. SRM is a type of effect size defined as a ratio of observed mean change and the standard deviation of change [37]. Values of $0.20,0.50$, and 0.80 or greater have been proposed to represent small, moderate, and large change, respectively [37]. All these analyses were performed for the total sample and stratified by type of deformity Class II or III. Change between Class II and Class III was compared by unpaired t-test. A database was created for statistical analysis using Stata Software [Stata Corp 2015, College Station, TX, USA].

\section{Results}

In total, 90 patients were included in the study during their pre-surgical orthodontic treatment and 73 subjects completed the two follow-ups at 3 and 6 months post-surgery (81.1\% response rate). Drop-outs to follow-up are mostly due to the postponement of clinical visits for elective controls during the height of the SARS-CoV-2 pandemic.

Table 1 shows patient characteristics: age mean was $23.28 \pm 5.7$, most of the participants were female $(71.2 \%)$ and reported having started or completed university studies (67.1\%). The main motivation for treatment was aesthetics and functional $(60.3 \%)$, followed by only functional motivation (37\%). Patients diagnosed as Class III were 53.4\%, and statistically significant differences for treatment motivation were found between patients in Class II and Class III $(p=0.041)$. In Class II, the motivation was only functional for half of the patients, while it was mainly the combination of aesthetics and functional (69.2\%) for Class III patients.

Table 2 shows mean scores, both global and per dimensions, of generic and oral HRQL instruments at baseline (pre-surgery), 3 and 6 months post-surgery follow-up, and mean changes between pre- and post-surgery. Negative mean changes indicate improvement. Almost all dimensions of the OQLQ and OHIP-14 showed statistically significant improvements at 3 and 6 months after surgery, compared with the pre-surgical evaluation. The SF-36v2 showed statistically significant improvement only in the physical component summary at 6 months after surgery. The OQLQ presented the highest Standardized Response Means (SRMs), the SF-36v2 the lowest. At 6 months post-surgery the largest SRM were found in OQLQ oral function (-1.11) and dentofacial facial aesthetics (-0.76) dimensions, SRM was moderate in most of OHIP-14 dimensions except for functional limitations and handicap (-0.30 in both). The largest SRM on SF-36v2 scores (0.46) was observed on the Physical Component Summary (PCS).

Table 3 shows the mean and mean changes between pre- and post-surgery global scores according to the type of dentofacial deformity. Mean change of OQLQ and OHIP-14 was statistically significant 3 months and 6 months after surgery in both types of deformity. At 6 months after surgery, mean change of SF-36v2 PCS was also statistically significant. Differences in mean change between Class II and III 
Table 1 Characteristics of patients according to type of deformity and follow-up completion

\begin{tabular}{|c|c|c|c|c|c|}
\hline Patient characteristics & $\begin{array}{l}\text { Patients with } \\
\text { follow-up com- } \\
\text { pleted }\end{array}$ & Class II patients & Class III patients & $p$ value* & $\begin{array}{l}\text { Patients not } \\
\text { completing } \\
\text { follow-up }\end{array}$ \\
\hline Number of patients & 73 & 34 & 39 & & 17 \\
\hline $\begin{array}{l}\text { Age, year mean }(\mathrm{SD}) \\
\text { range, } \mathrm{n}(\%)\end{array}$ & $23.28(5.7)$ & $22.88(5.2)$ & $23.64(6.2)$ & & $24.52(5.5)$ \\
\hline $18-20$ & $36(49.3 \%)$ & $18(52.9 \%)$ & $18(46.1 \%)$ & \multirow[t]{2}{*}{$0.563^{\mathrm{a}}$} & \\
\hline $21-42$ & $37(50.7 \%)$ & $16(47.1 \%)$ & $21(53.9 \%)$ & & \\
\hline \multicolumn{6}{|l|}{ Gender, n (\%) } \\
\hline Female & $52(71.23)$ & $24(70.6)$ & $28(71.8)$ & \multirow[t]{2}{*}{$0.910^{\mathrm{a}}$} & $10(58.8)$ \\
\hline Male & $21(28.77)$ & $10(29.4)$ & $11(28.2)$ & & $7(41.2)$ \\
\hline \multicolumn{6}{|l|}{ Education, $\mathrm{n}(\%)$} \\
\hline Secondary & $12(16.44)$ & $7(20.6)$ & $5(12.8)$ & \multirow[t]{4}{*}{$0.862^{\mathrm{b}}$} & $2(11.8)$ \\
\hline Technic & $8(10.96)$ & $3(8.8)$ & $5(12.8)$ & & $1(5.8)$ \\
\hline University & $49(67.12)$ & $22(64.7)$ & $27(69.3)$ & & $12(70.6)$ \\
\hline Postgraduate & $4(5.48)$ & $2(5.9)$ & $2(5.1)$ & & $2(11.8)$ \\
\hline \multicolumn{6}{|l|}{ Type of deformity, n (\%) } \\
\hline Class II & $34(46.58)$ & & & & \\
\hline Class III & $39(53.42)$ & & & & \\
\hline \multicolumn{6}{|c|}{ Motivation for treatment, $\mathrm{n}(\%)$} \\
\hline aesthetics & $2(2.74)$ & 0 & $2(5.1)$ & \multirow[t]{3}{*}{$0.041^{\mathrm{b}}$} & 0 \\
\hline functional & 27 (36.99) & $17(50)$ & $10(25.7)$ & & $4(23.5)$ \\
\hline both & $44(60.27)$ & $17(50)$ & $27(69.2)$ & & $13(76.5)$ \\
\hline
\end{tabular}

${ }^{* a}$ Chi-squared, ${ }^{b}$ Fisher's exact tests differences between class II and III were statistically significant for OQLQ (-10.08 vs -20.30 , $p=0.0271)$ and OHIP-14 (-3.79 vs $-10.56, p=0.0144)$.

Table 4 shows the distribution of responses to the Global Transition Scale on oral health. At 3 months after surgery, $60.71 \%$ of Class II patients indicated improvement, $32.1 \%$ worsening, and $7.1 \%$ stability. The number of Class II patients who reported worsening decreased to 0 at 6 months after surgery. None of Class III patients claimed to have worsened their condition, with the majority reporting improvement at both follow-ups: $90.0 \%$ at 3 months and $91.18 \%$ at 6 months.

\section{Discussion}

Our study showed improvements in oral health-related quality of life and also in the physical component of general health in patients with dentofacial deformities at 3 and 6 months after orthognathic surgery, with statistically significant differences between Class II and Class III. Although patients in both classes of dentofacial deformity presented an improvement, the increase was clearly higher for Class III patients than for Class II, especially in the first follow-up 3 months after surgery (score mean change of OQLQ -15.76 vs -7.23; of OHIP-14 -3.29 vs -8.69). Consistently, patients in Class III reported improvement in the global transition scale, from $90 \%$ at 3 months to $91.18 \%$ at 6 months, compared with $60.71 \%$ and $96.66 \%$ of patients in Class II.

OQLQ mean change from pre-surgery was higher at 6 months than at 3 months after surgery in our sample. Considering the magnitude of change indicated by the SRM, the improvement was moderate at 3 months after surgery in the OQLQ dimensions of dentofacial aesthetics and oral function, increasing to large at 6 months. This gradual postsurgical improvement was also found by Choi et al. (2010) [16] and Eslamipour et al. (2017) [13], who reported moderate to large improvement from 3 to 6 months post-surgery follow-up. These gradual changes could be expected by the normal postoperative clinical evolution. However, the OHIP14 did not show this gradual pattern of change, except for improvement on physical pain, which increased from small magnitude at 3 months to moderate at 6 months.

Frequently the studies show that the main motivation for surgical treatment is to improve facial aesthetics [31, 38], although Baherimoghaddam et al. [20] reported that certain patients prefer to improve function. Patients in our study reported both, aesthetics and functional, as a priori motivations for orthognathic surgery, which was consistent with the most impaired OQLQ dimensions at baseline (dentofacial aesthetics and oral function), and also with the greatest treatment benefits obtained in these dimensions (large improvements, $\mathrm{SRM}=-0.76$ and -1.1 , 
Table 2 Mean scores at three times: before surgery (T1), 3 months (T2) and 6 months after orthognathic surgery (T3); and mean changes between pre and post-surgery $(n=73)$

\begin{tabular}{|c|c|c|c|c|c|c|c|c|}
\hline \multirow[t]{2}{*}{ Instruments } & \multirow{2}{*}{$\begin{array}{l}\text { T1 } \\
\text { Mean (SD) }\end{array}$} & \multirow{2}{*}{$\begin{array}{l}\text { T2 } \\
\text { Mean (SD) }\end{array}$} & \multirow{2}{*}{$\begin{array}{l}\text { T3 } \\
\text { Mean (SD) }\end{array}$} & \multicolumn{3}{|l|}{ CHANGE (T2-T1) } & \multicolumn{2}{|l|}{ CHANGE (T3-T1) } \\
\hline & & & & Mean change (SD) & $p^{*}$ & SRM & Mean change (SD) & SRM \\
\hline OQLQ Global Score & $\begin{array}{l}40.71 \\
(19.13)\end{array}$ & $\begin{array}{l}28.91 \\
(17.27)\end{array}$ & $\begin{array}{l}25.16 \\
(16.79)\end{array}$ & $\begin{array}{l}-11.79 \\
(20.20)\end{array}$ & $<0.001$ & -0.58 & $\begin{array}{l}-15.54 \\
(19.83)\end{array}$ & $<0.001-0.78$ \\
\hline $\begin{array}{l}\text { Social aspects of } \\
\text { deformity }\end{array}$ & $\begin{array}{l}11.67 \\
(8.82)\end{array}$ & $\begin{array}{l}8.90 \\
(7.75)\end{array}$ & $\begin{array}{l}7.31 \\
(6.83)\end{array}$ & $\begin{array}{l}-2.76 \\
(8.28)\end{array}$ & 0.0056 & -0.33 & $\begin{array}{l}-4.35 \\
(8.52)\end{array}$ & $<0.001-0.51$ \\
\hline Dentofacial aesthetics & $\begin{array}{l}11.34 \\
(5.14)\end{array}$ & $\begin{array}{l}7.56 \\
(4.70)\end{array}$ & $\begin{array}{l}6.91 \\
(4.99)\end{array}$ & $\begin{array}{l}-3.78 \\
(5.76)\end{array}$ & $<0.001$ & -0.66 & $\begin{array}{l}-4.42 \\
(5.82)\end{array}$ & $<0.001-0.76$ \\
\hline Oral function & $\begin{array}{l}11.04 \\
(4.79)\end{array}$ & $\begin{array}{l}6.53 \\
(4.37)\end{array}$ & $\begin{array}{l}5.09 \\
(4.42)\end{array}$ & $\begin{array}{l}-4.5 \\
(6.19)\end{array}$ & $<0.001$ & -0.73 & $\begin{array}{l}-5.94 \\
(5.37)\end{array}$ & $<0.001-1.11$ \\
\hline $\begin{array}{l}\text { Awareness of facial } \\
\text { deformity }\end{array}$ & $\begin{array}{l}6.65 \\
(4.23)\end{array}$ & $\begin{array}{l}5.91 \\
(4.32)\end{array}$ & $\begin{array}{l}5.83 \\
(4.48)\end{array}$ & $\begin{array}{l}-0.75 \\
(4.50)\end{array}$ & 0.1650 & -0.17 & $\begin{array}{l}-0.82 \\
(4.49)\end{array}$ & $0.1226-0.18$ \\
\hline OHIP-14 Global Score & $16.32(10.09)$ & $\begin{array}{l}10.15 \\
(7.89)\end{array}$ & $\begin{array}{l}8.91 \\
(8.57)\end{array}$ & $\begin{array}{l}-6.17 \\
(10.06)\end{array}$ & $<0.001$ & -0.61 & $\begin{array}{l}-7.41 \\
(11.91)\end{array}$ & $<0.001-0.62$ \\
\hline Functional limitation & $1.5(1.75)$ & $\begin{array}{l}1.08 \\
(1.41)\end{array}$ & $\begin{array}{l}0.95 \\
(1.54)\end{array}$ & $\begin{array}{l}-0.49 \\
(1.70)\end{array}$ & 0.0156 & -0.29 & $\begin{array}{l}-0.61 \\
(2.06)\end{array}$ & $0.0129-0.30$ \\
\hline Physical pain & $3.39(1.83)$ & $\begin{array}{l}3.02 \\
(1.85)\end{array}$ & $\begin{array}{l}2.38 \\
(1.82)\end{array}$ & $\begin{array}{l}-0.36 \\
(1.77)\end{array}$ & 0.0793 & -0.20 & $\begin{array}{l}-1.01 \\
(1.90)\end{array}$ & $<0.001-0.53$ \\
\hline $\begin{array}{l}\text { Psychological dis- } \\
\text { comfort }\end{array}$ & $3.01(2.24)$ & $\begin{array}{l}1.57 \\
(1.71)\end{array}$ & $\begin{array}{l}1.64 \\
(1.88)\end{array}$ & $\begin{array}{l}-1.43 \\
(2.45)\end{array}$ & $<0.001$ & -0.58 & $\begin{array}{l}-1.36 \\
(2.62)\end{array}$ & $<0.001-0.52$ \\
\hline Physical disability & $2.83(2.21)$ & $\begin{array}{l}1.45 \\
(1.65)\end{array}$ & $\begin{array}{l}1.39 \\
(1.80)\end{array}$ & $\begin{array}{l}-1.38 \\
(2.05)\end{array}$ & $<0.001$ & -0.67 & $\begin{array}{l}-1.43 \\
(2.61)\end{array}$ & $<0.001-0.55$ \\
\hline $\begin{array}{l}\text { Psychological dis- } \\
\text { ability }\end{array}$ & $2.72(2.13)$ & $\begin{array}{l}1.41 \\
(1.69)\end{array}$ & $\begin{array}{l}1.27 \\
(1.41)\end{array}$ & $\begin{array}{l}-1.31 \\
(2.19)\end{array}$ & $<0.001$ & -0.69 & $\begin{array}{l}-1.45 \\
(2.48)\end{array}$ & $<0.001-0.58$ \\
\hline Social disability & $1.82(2.03)$ & $\begin{array}{l}1.04 \\
(1.51)\end{array}$ & $0.83(1.37)$ & $\begin{array}{l}-0.78 \\
(1.90)\end{array}$ & $<0.001$ & -0.41 & $\begin{array}{l}-0.98 \\
(2.15)\end{array}$ & $<0.001-0.46$ \\
\hline Handicap & $0.95(1.53)$ & $\begin{array}{l}0.56 \\
(1.14)\end{array}$ & $0.42(1.22)$ & $\begin{array}{l}-0.39 \\
(1.65)\end{array}$ & 0.0441 & -0.24 & $\begin{array}{l}-0.53 \\
(1.77)\end{array}$ & $0.0121-0.30$ \\
\hline \multicolumn{9}{|c|}{ Short-Form 36v2 Global Score } \\
\hline Physical Functioning & $93.35(10.03)$ & $\begin{array}{l}94.58 \\
(12.74)\end{array}$ & $96.71(8.54)$ & $\begin{array}{l}1.23 \\
(14.71)\end{array}$ & 0.4766 & 0.08 & $\begin{array}{l}3.35 \\
(8.86)\end{array}$ & 0.00180 .38 \\
\hline Role-Physical & $87.87(17.16)$ & $\begin{array}{l}87.75 \\
(17.13)\end{array}$ & $92.89(12.98)$ & $\begin{array}{l}-0.11 \\
(17.09)\end{array}$ & 0.9547 & -0.01 & $\begin{array}{l}5.02 \\
(15.86)\end{array}$ & 0.00850 .32 \\
\hline Bodily Pain & $77.27(20.93)$ & $\begin{array}{l}78.79 \\
(19.17)\end{array}$ & $83.91(20.46)$ & $\begin{array}{l}1.52 \\
(24.62)\end{array}$ & 0.5994 & 0.06 & $\begin{array}{l}6.64 \\
(23.50)\end{array}$ & 0.01830 .28 \\
\hline General Health & $76.47(16.20)$ & $\begin{array}{l}80.47 \\
(15.08)\end{array}$ & $80.75(17.57)$ & $\begin{array}{l}4 \\
(13.58)\end{array}$ & 0.0141 & 0.29 & $\begin{array}{l}4.27 \\
(15.22)\end{array}$ & 0.01910 .28 \\
\hline Vitality & $64.29(21.88)$ & $\begin{array}{l}64.38 \\
(20.37)\end{array}$ & $67.12(19.90)$ & $\begin{array}{l}0.08 \\
(20.13)\end{array}$ & 0.9711 & 0.00 & $\begin{array}{l}2.82 \\
(22.14)\end{array}$ & 0.27940 .13 \\
\hline Social Functioning & $82.19(18.03)$ & $\begin{array}{l}82.19 \\
(19.08)\end{array}$ & $84.41(22.70)$ & $\begin{array}{l}0 \\
(22.04)\end{array}$ & 1 & 0.00 & $\begin{array}{l}2.22 \\
(23.23)\end{array}$ & 0.41570 .10 \\
\hline Role Emotional & $85.15(18.49)$ & $\begin{array}{l}88.01 \\
(16.54)\end{array}$ & $86.18(21.07)$ & $\begin{array}{l}2.85 \\
(19.50)\end{array}$ & 0.2154 & 0.15 & $\begin{array}{l}1.02 \\
(22.43)\end{array}$ & 0.69670 .05 \\
\hline Mental Health & $74.65(16.63)$ & $\begin{array}{l}74.45 \\
(18.53)\end{array}$ & $74.10(18.64)$ & $\begin{array}{c}-0.20 \\
(19.10)\end{array}$ & 0.9270 & -0.01 & $\begin{array}{c}-0.54 \\
(22.38)\end{array}$ & $0.8349-0.02$ \\
\hline $\begin{array}{l}\text { SF-36v2 Physical } \\
\text { Health Component } \\
\text { Summary }\end{array}$ & $55.28(5.23)$ & $\begin{array}{l}55.93 \\
(5.04)\end{array}$ & $57.82(5.25)$ & $\begin{array}{l}0.65 \\
(6.13)\end{array}$ & 0.3675 & 0.11 & $\begin{array}{l}2.54 \\
(5.54)\end{array}$ & $<0.0010 .46$ \\
\hline $\begin{array}{l}\text { SF-36v2 Mental } \\
\text { Health Component } \\
\text { Summary }\end{array}$ & $49.33(9.15)$ & $\begin{array}{l}49.61 \\
(9.51)\end{array}$ & $49.12(11.04)$ & $\begin{array}{l}0.28 \\
(9.67)\end{array}$ & 0.8040 & 0.03 & $\begin{array}{c}-0.20 \\
(11.66)\end{array}$ & $0.8797-0.02$ \\
\hline
\end{tabular}

$S R M$ standardized response mean

*paired $t$-test 


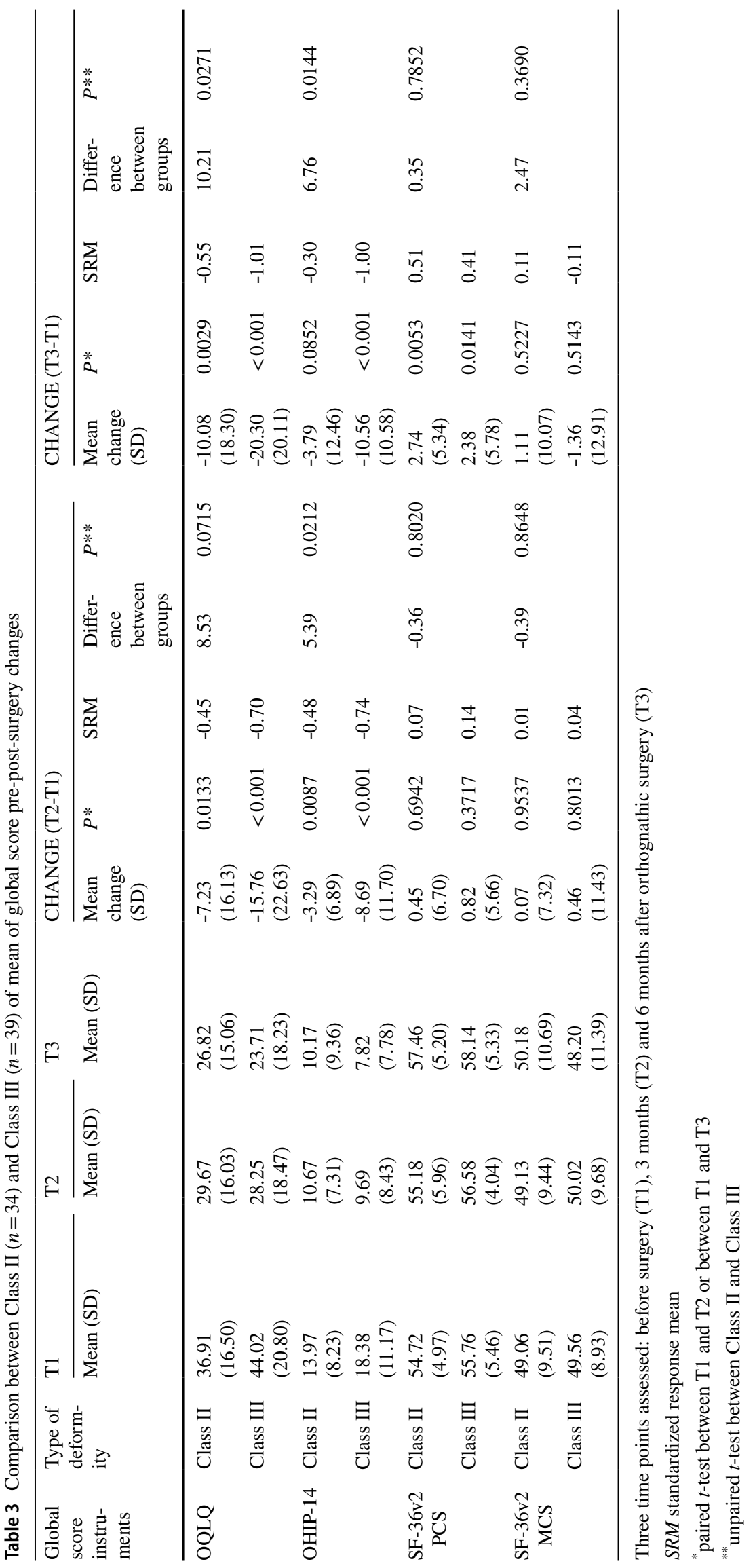


Table 4 Responses to the Global Transition Scale by type of deformity and follow-up time

\begin{tabular}{|c|c|c|c|c|}
\hline \multirow[t]{3}{*}{ Global rating } & \multicolumn{2}{|l|}{$\mathrm{T} 2$} & \multicolumn{2}{|l|}{ T3 } \\
\hline & Class II $(n=28)$ & Class III $(n=30)$ & Class II $(n=30)$ & Class III $(n=34)$ \\
\hline & $n(\%)$ & $n(\%)$ & $n(\%)$ & $n(\%)$ \\
\hline Has improved & $17(60.71)$ & $27(90)$ & $29(96.66)$ & $31(91.18)$ \\
\hline A very great deal better & $9(32.14)$ & $11(36.67)$ & $10(33.33)$ & $14(41.18)$ \\
\hline A great deal better & $6(21.43)$ & $5(16.675)$ & $6(20)$ & $5(14.71)$ \\
\hline A good deal better & 0 & $6(20)$ & $9(30)$ & $6(17.65)$ \\
\hline Moderately better & 0 & $4(13.33)$ & $1(3.33)$ & $4(11.76)$ \\
\hline Somewhat better & 0 & 0 & $3(10)$ & $1(2.94)$ \\
\hline A little better & $2(7.14)$ & $1(3.33)$ & 0 & $1(2.94)$ \\
\hline Practically the same & $2(7.14)$ & $3(10)$ & $1(3.33)$ & $3(8.82)$ \\
\hline Almost the same, hardly any better at all & 0 & 0 & 0 & $2(5.88)$ \\
\hline No change & $2(7.14)$ & $3(10)$ & $1(3.33)$ & $1(2.94)$ \\
\hline Almost the same, hardly any worse at all & 0 & 0 & 0 & 0 \\
\hline It has worsened & $9(32.14)$ & 0 & 0 & 0 \\
\hline A very great deal worse & 0 & 0 & 0 & 0 \\
\hline A great deal worse & 0 & 0 & 0 & 0 \\
\hline A good deal worse & $5(17.86)$ & 0 & 0 & 0 \\
\hline Moderately worse & $1(3.57)$ & 0 & 0 & 0 \\
\hline Somewhat worse & $2(7.14)$ & 0 & 0 & 0 \\
\hline A little worse & $1(3.57)$ & 0 & 0 & 0 \\
\hline$P$ value* & 0.001 & & 0.616 & \\
\hline
\end{tabular}

T2: 3 months after surgery, T3: 6 months after surgery

*Fisher's exact test to compare between Class II and Class III

respectively). Studies with similar follow-up times to ours (before surgery and 6 months post-surgery) also found large improvements in dentofacial aesthetics $[13,16,31$, $39]$ and oral function [16, 31, 39]. Furthermore, most of these studies reported moderate improvement in the social domain [13, 16, 39] and small on awareness [16, 31, 39], the same magnitude of improvement observed in our sample 6 months after surgery.

It is especially remarkable the moderate to small improvement observed in the four physical health domains of the SF-36v2 at 6 months after surgery (SRM 0.38 in physical functioning, 0.32 in role-physical, 0.28 in bodily pain and general health), as well as the moderate improvement in the Physical Health Component Summary that collects mainly these four dimensions for both Class II and III (SRM 0.51 and 0.41). A study of patients with Angle's Class III malocclusion showed statistically significant improvement after orthognathic surgery on physical and social domains of SF36v1 [40]. However, other two studies reported a significant but transient deterioration in the SF-36v1 Physical and Mental component summaries at 6 weeks after surgery [16] [39], which returned to baseline levels at 6 months after surgery[39] or at the end of orthodontic treatment [16]. We did not observe this deterioration in the first assessment
3 months post-surgery, but we could not be sure that it occurs due to the lack of evaluation at 6 weeks.

We observed a greater improvement in Class III patients compared to Class II in oral health-related quality of life measured with OQLQ and OHIP-14 global scores. Our results are in accordance with those from the two studies that analyzed the change according to diagnostic group, measuring the oral health-related quality of life with the OQLQ $[13,19]$, and the two studies [19-21] measuring it with the OHIP-14, that also showed this pattern of greater improvement among Class III patients than Class II.

A study with the Body Image Assessment Questionnaire showed that the psychologic profiles are significantly different between Class II and Class III patients preoperatively [22]: the latter felt significantly less attractive, reported slightly higher attention and insecurity regarding their physical appearance. Another study with the Minnesota Multiphasic Personality Inventory showed higher depression score in Class III than in Class II groups [41]. Findings of these two studies $[22,41]$ are consistent with the worse oral HRQoL in Class III vs Class II patients of our study before surgery (with score means of 44.02 vs 36.9 in the OQLQ and 18.38 vs 13.97 in the OHIP-14) and also with their different postoperative dynamics. This suggests that the fact that Class 
III patients presented a greater impact before surgery, partly explains their greater improvement between pre- and postorthognathic surgery.

The main limitation of the study is the baseline measurement, which was performed just before surgery. To assess the impact of conventional three-phase treatment for dentofacial deformities (pre-surgical orthodontics, surgery and post-surgical orthodontics), it would have been ideal to carry out the baseline measurement prior to the installation of orthodontic devices, and to finalize the follow-up after removing post-surgical orthodontics, which would have required at least 2 to 3 years. This longer ideal follow-up could not be applied in our study due to time and financial restrictions. Nevertheless, most of the few studies applying this ideal design also showed large improvement on dentofacial aesthetics $[11,16]$ and oral function $[16,42]$, and moderate on social [11,42], with more variability on awareness, which showed moderate improvement in some studies [16, 42] but negligible in another one [11].

Second, because our study included mainly young women with university studies, the generalizability of our results regarding gender and social class is uncertain. Women with dentofacial deformities have shown a lower perception of quality of life compared to men and a stronger motivation for surgical treatment [43], with studies presenting up to a "2 to 1 ratio" in favor of women $[43,44]$. This surgery is usually prescribed in young adults, once their growth is finished, but its coverage by the Chilean public health system is very restrictive. The high percentage of individuals with university studies in our sample reflects the socioeconomic bias of accessing this treatment privately.

While the existing literature supports the positive impact of orthognathic surgery in oral health-related quality of life, our study is the first analyzing by type of dentofacial deformities with generic, further than oral-specific, health-related quality of life instruments and a global transition scale. The Global Transition Scale has been used only in one previous orthognathic surgery study [31] which did not differentiate by class.

\section{Conclusion}

A significant improvement was observed in oral healthrelated quality of life and also in the physical component of general health in patients with dentofacial deformities Class II and III at 3 and 6 months after orthognathic surgery. Improvement was greater in Class III than in Class II patients. These results provide patients, oral health care professionals, and health care planners with valuable information to make evidence-based decisions and facilitate shared clinical decision-making, taking into account the patients' perspective.
Acknowledgements For their fundamental support of this study, we thank to Leonor, María Isabel, Silvana, Julia, Fernando, Moni and Fiona. The authors would like to thank Aurea Martin for her support in English editing, proofreading, and preparing this manuscript for submission. Especial thanks to our patients who collaborated with this project and the participating Institutions.

Author contribution The authors have critically reviewed the manuscript and agreed to its submission. VD, MF, CZ, and JV conceived, conceptualized, and designed the study. CV, PS, RR, JO, MD, RR and $\mathrm{MB}$ conducted the coordination of the study in each center and collected follow-up data. VD, CZ, and FW analyzed the data. VD, CZ, and MF drafted the manuscript, and all authors read and contributed to the final manuscript and agreed to its publication.

\section{Declarations}

Ethics approval This study was performed in line with the principles of the Declaration of Helsinki. Approval was granted by the Ethics Committee Valparaíso-San Antonio Health Service (30-11-18 / No 2436).

Consent to participate Informed consent was obtained from all individual participants included in the study.

Conflict of interest The authors declare no competing interests.

\section{References}

1. Arnett GW, Jelic JS, Kim J et al (1999) Soft tissue cephalometric analysis: diagnosis and treatment planning of dentofacial deformity. Am J Orthod Dentofac Orthop 116:239-253. https://doi.org/ 10.1016/S0889-5406(99)70234-9

2. Rizzatto SMD, Macedo de Menezes L, da Cunha Filho JJ, Allgayer S (2018) Conventional surgical-orthodontic approach with double-jaw surgery for a patient with a skeletal Class III malocclusion: stability of results 10 years posttreatment. Am J Orthod Dentofac Orthop 154:128-139. https://doi.org/10.1016/j.ajodo. 2016.12.034

3. Seifi M, Matini N-S, Motabar A-R, Motabar M (2018) Dentoskeletal stability in conventional orthognathic surgery, presurgical orthodontic treatment and surgery-first approach in class-III patients. World J Plast Surg 7:283-293. https://doi.org/10.29252/ wjps.7.3.283

4. Luther F, Morris DO, Karnezi K (2007) Orthodontic treatment following orthognathic surgery: how long does it take and why? A retrospective study. J Oral Maxillofac Surg 65:1969-1976. https:// doi.org/10.1016/j.joms.2007.05.026

5. Dehghani M, Fazeli F, Sattarzadeh AP (2017) Efficiency and duration of orthodontic/orthognathic surgery treatment. J Craniofac Surg 28:1997-2000. https://doi.org/10.1097/SCS.0000000000 004165

6. Dowling PA, Espeland L, Krogstad O et al (1999) Duration of orthodontic treatment involving orthognathic surgery. Int J Adult Orthodon Orthognath Surg 14:146-152

7. Guyatt GH, Feeny DH, Patrick DL (1993) Measuring healthrelated quality of life. Ann Intern Med 118:622-629. https://doi. org/10.7326/0003-4819-118-8-199304150-00009

8. Morris J, Perez D, McNoe B (1998) The use of quality of life data in clinical practice. Qual Life Res Int J Qual Life Asp Treat Care Rehab 7:85-91. https://doi.org/10.1023/a:1008893007068

9. Middel B, van Sonderen E (2002) Statistical significant change versus relevant or important change in (quasi) experimental 
design: some conceptual and methodological problems in estimating magnitude of intervention-related change in health services research. Int J Integr Care 2:e15. https://doi.org/10.5334/ijic.65

10. Cunningham SJ, Garratt AM, Hunt NP (2000) Development of a condition-specific quality of life measure for patients with dentofacial deformity: I. Reliability of the instrument. Community Dent Oral Epidemiol 28:195-201. https://doi.org/10.1034/j.1600-0528. 2000.280305.x

11. Cunningham SJ, Garratt AM, Hunt NP (2002) Development of a condition-specific quality of life measure for patients with dentofacial deformity: II. Validity and responsiveness testing. Community Dent Oral Epidemiol 30:81-90. https://doi.org/10. 1034/j.1600-0528.2002.300201.x

12. Duarte V, Zaror C, Villanueva J et al (2020) Cross-cultural adaptation and validation of the Spanish version of the orthognathic qality of life questionnaire for patients with dentofacial deformities. J Cranio-Maxillofac Surg 48:1112-1118. https://doi.org/10. 1016/j.jcms.2020.10.004

13. Eslamipour F, Najimi A, Tadayonfard A, Azamian Z (2017) Impact of orthognathic surgery on quality of life in patients with dentofacial deformities. Int J Dent 2017:1-6. https://doi.org/10. $1155 / 2017 / 4103905$

14. Kavin T, Jagadesan AG, Venkataraman S (2012) Changes in quality of life and impact on patients' perception of esthetics after orthognathic surgery. J Pharm Bioallied Sci 4:290. https://doi. org/10.4103/0975-7406.100276

15. Khadka A, Liu Y, Li J et al (2011) Changes in quality of life after orthognathic surgery: a comparison based on the involvement of the occlusion. Oral Surg Oral Med Oral Pathol Oral Radiol Endod 112:719-725. https://doi.org/10.1016/j.tripleo.2011.01.002

16. Choi WS, Lee S, McGrath C, Samman N (2010) Change in quality of life after combined orthodontic-surgical treatment of dentofacial deformities. Oral Surg Oral Med Oral Pathol Oral Radiol Endod 109:46-51. https://doi.org/10.1016/j.tripleo.2009.08.019

17. Chaurasia N, Upadhyaya C, Srivastava S, Dulal S (2018) Assessment of changes in quality of life in patients with dentofacial deformities after orthognathic surgery-a study in Nepalese population. J Oral Maxillofac Surg Med Pathol 30:111-114. https://doi. org/10.1016/j.ajoms.2017.10.005

18. Cunningham SJ, Sculpher M, Sassi F, Manca A (2003) A costutility analysis of patients undergoing orthognathic treatment for the management of dentofacial disharmony. Br J Oral Maxillofac Surg 41:32-35. https://doi.org/10.1016/S0266-4356(02)00285-1

19. Sun H, Shang H, He L et al (2018) Assessing the quality of life in patients with dentofacial deformities before and after orthognathic surgery. J Oral Maxillofac Surg 76:2192-2201. https://doi.org/10. 1016/j.joms.2018.03.026

20. Baherimoghaddam T, Tabrizi R, Naseri N et al (2016) Assessment of the changes in quality of life of patients with class II and III deformities during and after orthodontic-surgical treatment. Int J Oral Maxillofac Surg 45:476-485. https://doi.org/10.1016/j.ijom. 2015.10.019

21. Göelzer JG, Becker OE, Haas Junior OL et al (2014) Assessing change in quality of life using the Oral Health Impact Profile (OHIP) in patients with different dentofacial deformities undergoing orthognathic surgery: a before and after comparison. Int J Oral Maxillofac Surg 43:1352-1359. https://doi.org/10.1016/j. ijom.2014.06.015

22. Gerzanic L, Jagsch R, Watzke IM (2002) Psychologic implications of orthognathic surgery in patients with skeletal Class II or Class ill malocclusion. Int J Adult Orthodon Orthognath Surg 17:75-81

23. Miguel JAM, Palomares NB, Feu D (2014) Life-quality of orthognathic surgery patients: the search for an integral diagnosis. Dent Press J Orthod 19:123-137. https://doi.org/10.1590/2176-9451. 19.1.123-137.sar
24. Angle E (1899) Classification of malocclusion. Dent Cosm $41: 248-264$

25. Joshi, (2014) Skeletal malocclusion: a developmental disorder with a life-long morbidity. J Clin Med Res. https://doi.org/10. 14740/jocmr1905w

26. Rédua RB (2020) Different approaches to the treatment of skeletal class II malocclusion during growth: bionator versus extraoral appliance. Dent Press J Orthod 25:69-85. https://doi.org/10.1590/ 2177-6709.25.2.069-085.bbo

27. Fakharian M, Bardideh E, Abtahi M (2019) Skeletal Class III malocclusion treatment using mandibular and maxillary skeletal anchorage and intermaxillary elastics: a case report. Dent Press J Orthod 24:52-59. https://doi.org/10.1590/2177-6709.24.5.052059.oar

28. Montero-Martín J, Bravo-Pérez M, Albaladejo-Martínez A et al (2009) Validation the Oral Health Impact Profile (OHIP-14sp) for adults in Spain. Med Oral Patol Oral Cirugia Bucal 14:E44-50

29. Ware JE, Sherbourne CD (1992) The MOS 36-item short-form health survey (SF-36). I. Conceptual framework and item selection. Med Care 30:473-483

30. Al-Asfour A, Waheedi M, Koshy S (2018) Survey of patient experiences of orthognathic surgery: health-related quality of life and satisfaction. Int J Oral Maxillofac Surg 47:726-731. https://doi. org/10.1016/j.ijom.2017.12.010

31. Murphy C, Kearns G, Sleeman D et al (2011) The clinical relevance of orthognathic surgery on quality of life. Int J Oral Maxillofac Surg 40:926-930. https://doi.org/10.1016/j.ijom.2011.04. 001

32. Fayers PM, Machin D (2000) Quality of life: assessment, analysis, and interpretation. Wiley, Chichester

33. León S, Bravo-Cavicchioli D, Correa-Beltrán G, Giacaman RA (2014) Validation of the Spanish version of the Oral Health Impact Profile (OHIP-14Sp) in elderly Chileans. BMC Oral Health 14:95. https://doi.org/10.1186/1472-6831-14-95

34. Alonso J, Regidor E, Barrio G et al (1998) Population reference values of the Spanish version of the health questionnaire SF-36. Med Clin (Barc) 111:410-416. https://doi.org/10.1016/S00257753(03)73775-0

35 Farivar SS, Cunningham WE, Hays RD (2007) Correlated physical and mental health summary scores for the SF-36 and SF-12 Health Survey, V.I. Health Qual Life Outcomes 5:54. https://doi. org/10.1186/1477-7525-5-54

36. Juniper E (1994) Determining a minimal important change in a disease-specific quality of life questionnaire. J Clin Epidemiol 47:81-87. https://doi.org/10.1016/0895-4356(94)90036-1

37. Hevey D, McGee HM (1998) The effect size statistic: useful in health outcomes research? J Health Psychol 3:163-170. https:// doi.org/10.1177/135910539800300201

38. Rustemeyer J, Gregersen J (2012) Quality of Life in orthognathic surgery patients: post-surgical improvements in aesthetics and self-confidence. J Cranio-Maxillofac Surg 40:400-404. https:// doi.org/10.1016/j.jcms.2011.07.009

39. Lee S, McGrath C, Samman N (2008) Impact of orthognathic surgery on quality of life. J Oral Maxillofac Surg 66:1194-1199. https://doi.org/10.1016/j.joms.2008.01.006

40. Nicodemo D, Pereira MD, Ferreira LM (2008) Effect of orthognathic surgery for class III correction on quality of life as measured by SF-36. Int J Oral Maxillofac Surg 37:131-134. https://doi. org/10.1016/j.ijom.2007.07.024

41. Takatsuji H, Kobayashi T, Kojima T et al (2015) Effects of orthognathic surgery on psychological status of patients with jaw deformities. Int J Oral Maxillofac Surg 44:1125-1130. https://doi. org/10.1016/j.ijom.2015.02.003

42. Alanko O, Tuomisto MT, Peltomäki T et al (2017) A longitudinal study of changes in psychosocial well-being during orthognathic 
treatment. Int J Oral Maxillofac Surg 46:1380-1386. https://doi. org/10.1016/j.ijom.2017.05.004

43. Hugo B, Becker S, Witt E (1996) Assessment of the combined orthodontic- surgical treatment from the patients' point of view: a longitudinal study. J Orofac Orthop 57:88-101. https://doi.org/ 10.1007/BF02190482

44. Nurminen L (1999) Motivation for and satisfaction with orthodontic-surgical treatment: a retrospective study of 28 patients. Eur J Orthod 21:79-87. https://doi.org/10.1093/ejo/21.1.79
Publisher's note Springer Nature remains neutral with regard to jurisdictional claims in published maps and institutional affiliations.

\section{Authors and Affiliations}

\section{Valentina Duarte ${ }^{1,2,3}$ (D) $\cdot$ Carlos Zaror ${ }^{4,5} \cdot$ Julio Villanueva $^{6,7} \cdot$ Fabiola Werlinger $^{8} \cdot$ Constanza Vidal $^{2} \cdot$ Pedro Solé $^{9,10}$. Juan Alberto O`Ryan ${ }^{9} \cdot$ Roberto Requena $^{9,10}$ • Matías Dallaserra ${ }^{6} \cdot$ René Rojas $^{11} \cdot$ Marcela Burgos $^{12}$. Montse Ferrer ${ }^{13,14,15}$}

1 Pontificia Universidad Católica de Valparaíso, Valparaíso, Chile

2 Department of Oral \& Maxillofacial Surgery, Hospital Carlos Van Buren, San Ignacio 725, Valparaíso, Chile

3 Department of Paediatrics, Obstetrics and Gynaecology and Preventive Medicine, Universitat Autònoma de Barcelona, Barcelona, Spain

4 Department of Paediatric Dentistry and Orthodontic, Faculty of Dentistry, Universidad de La Frontera, Temuco, Chile

5 Center for Research in Epidemiology, Economics and Oral Public Health (CIEESPO), Faculty of Dentistry, Universidad de La Frontera, Temuco, Chile

6 Department of Oral \& Maxillofacial Surgery and Cochrane Associated Center, Faculty of Dentistry, Universidad de Chile, Santiago, Chile

7 Department of Oral \& Maxillofacial Surgery, Hospital Clínico San Borja-Arriarán, Santiago, Chile
8 Center for Epidemiology and Surveillance of Oral Disease (CEVEO), Faculty of Dentistry, Universidad de Chile, Santiago, Chile

9 Department of Oral \& Maxillofacial Surgery, Faculty of Dentistry, Universidad de los Andes, Santiago, Chile

10 Department of Oral \& Maxillofacial Surgery, Clínica Universidad de Los Andes, Santiago, Chile

11 Department of Oral \& Maxillofacial Surgery, Clínica Santa María, Santiago, Chile

12 Clinical Psychologist, Private Practice, Santiago, Chile

13 Health Services Research Group, IMIM (Hospital del Mar Medical Research Institute), Barcelona, Spain

14 CIBER en Epidemiología y Salud Pública, CIBERESP, Madrid, Spain

15 Department of Experimental and Health Sciences, Pompeu Fabra University, Barcelona, Spain 